International Review of Research in Open and Distributed Learning Volume 17, Number 4

June -2016

\title{
Guidelines for Transferring Residential Courses into Web
}

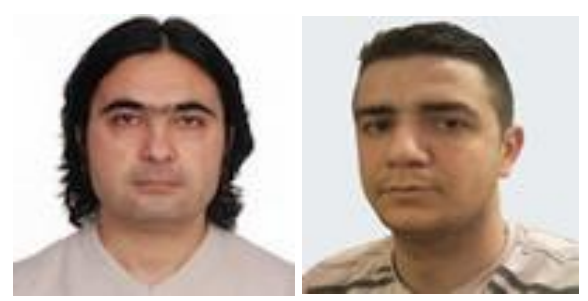

Hakan Tüzün and Murat Çınar

Hacettepe University, Department of Computer Education and Instructional Technology, Turkey

\begin{abstract}
This study shared unique design experiences by examining the process of transferring residential courses to the Web, and proposed a design model for individuals who want to transfer their courses into this environment. The formative research method was used in the study, and two project teams' processes of putting courses, which were being taught in classrooms at the time, on the Web were examined in depth to reveal and confirm the components of the design model. The participants were 13 instructional designers. In addition to the logbooks kept by the designers, individual and focus group interview techniques were employed in the data-gathering process. Two researchers analyzed the data concurrently using content analysis. The logbooks and the focus-group interviews were used for model formation, and the individual interviews to confirm the components of the model. Based on the findings from the two design cases, the experience-based e-course design model consisting of seven basic stages including forming design team, preliminary search, analysis, instructional and technical design, integration, tests, and improvements was proposed. It is considered that sustaining Web-based course design efforts within this model will enable both implementing the design process more effectively, and the Web-based course obtained at the end of the process to have higher quality.
\end{abstract}

Keywords: distance education, Web-based course design, e-course design, design model, formative research 


\section{Introduction}

Today, many institutions, organisations, and companies, particularly higher education institutions, organise Web-based courses and seminars because these environments provide learning practices that eliminate temporal and spatial limitations, reduce education costs, support multimedia, and are highly interactive. Teaching through the Web offers many opportunities to both learners and teachers. Many learners who suspended their education or dropped out due to the limitations of the traditional teaching approach can continue their education in a way that is more suitable to their lifestyles by means of Webbased instruction. However, conscientious analyses should be conducted to design teaching for the Web and to teach on the Web, and it should be examined how the potential of the Web can be used in accordance with the principles of instructional design (Ritchie \& Hoffman, 1997).

The Internet has long been used as a means of distributing and sharing information. On the other hand, there is a notable lack of sufficient research on how to convey teaching on the Internet environment (Burke, 2005; Tüzün, 2001).

Today, many instructors, especially those working at higher education institutions, are assigned to move their residential courses to the Web environment; however, they are compelled to do this transformation by trial-and-error due to a lack of sufficient research in the literature (Koontz, Li, \& Compora, 2006; Lightfoot, 2000). This produces electronic content that presents the curriculum content in sequence, but are not blended with the appropriate pedagogy. According to Snyder (2009), new instructional design theories and models are needed to design teaching using the new technology and tools that the Internet offers. Instructional designers need guidance about how to use these new tools and technologies effectively to develop learning and teaching in different environments (Koontz et al., 2006; Reigeluth, 1999).

Early studies of Web-based education (WBE) in the literature focused on identifying the components of successful WBE and how learning processes in an interactive environment can be directed (for instance Duchastel, 1996; Reeves \& Reeves, 1997; Ritchie \& Hoffman, 1997). These approaches were created by adapting classical instructional design processes to the Web environment and did not present information on how the design process would be implemented. Most studies that proposed a design route or design model for Web-based courses were adaptations of the regular software development processes to distance education (DE) course design (for instance Neuhauser, 2004; Zhou \& Zhou, 2009). On the other hand, other studies looked at DE course processes from a more organisational perspective and listed the steps of the design process in general (for instance Balc1, 2010; Tüzün, 2001).

Although these studies offer guidance for the process of Web-based instructional design and development, they do not include information about how design instructions should be implemented. In addition, they address neither the problems that can be encountered in the design process nor the solutions to these problems. As for studies based on authentic design cases, they describe the design process in a narrative way, rather than proposing a model (for instance Alvarez, Blair, Monske, \& Wolf, 2005; Power, 2009). 
The literature also contains collaborative design-based development approaches to the revision of existing online courses (for instance Kokić, Nevin, \& Malian, 2013; Swan, Day, Bogle, \& Matthews, 2014). Kokić et al. (2013) emphasised the importance of the collaboration between instructors and administrators in online course development to facilitate and improve learning and teaching practices. Their study, which analysed comparatively the changes in online teaching practices and course content in the process of giving an online course for seven semesters, points out that the teamwork conducted by both instructional designers and field experts is required for the initial design of an online course. In this approach, the former course instructors act as advisors who actively participate in the course revision process. The authors also highlighted that online courses require ongoing revisions due to changes in the subject field, pedagogical approaches, and technological advances, and organisational support and cooperation between instructors have an important place in this revision process. The model proposed by Swan et al. (2014) associates iterative and design-based improvements to learning outcomes in the online course design and development process. In this model, two step iterative processes, the quality matters rubrics and the community of inquiry framework, were used to make the initial online course design and then to address the issues that arose during the implementation of the course. However, since the model is intended for the redesign of courses that are already offered online, it does not provide enough guidance to transform traditional courses into Web-based courses or develop a new online course. Gazioğlu (2013) has shared experiences of the development of an online undergraduate course. However, this study addressed course design and development from a product-oriented perspective. The e-course design was limited to transfer of course materials onto online environment using a learning management system. In addition, the study focused more on introducing an e-course product at the end of the design process rather than the design process itself.

This study differs from other studies in the literature by both examining the design process with all the details based on authentic design cases and proposing a design model in the light of the design practices. It is hoped that this design model will guide designers in the process of preparing Web-based instructional applications.

\section{Research Questions}

1. What are the ways that should be followed in the Web-based design of a course delivered residentially or a new course?

1.1. What are the components of the instructional design and development process for Web-based courses?

1.2. How should these components be combined within the framework of a model to provide guidance for preparing Web-based courses?

\section{Methodology}

\section{The Model of the Study}

This study used the formative research method, which is a qualitative research method, to examine thoroughly the design process of adapting residential courses to the online environment. 
It takes the form of developmental research or action research which is observed in order to produce or develop a design theory, model, and applications (Reigeluth \& Frick, 1999). Naturalist design cases were used within the study (see Figure 1). Since the data-gathering process was initiated along with the natural course of the cases and continued until their end, the study is a form of in vivo naturalistic research.

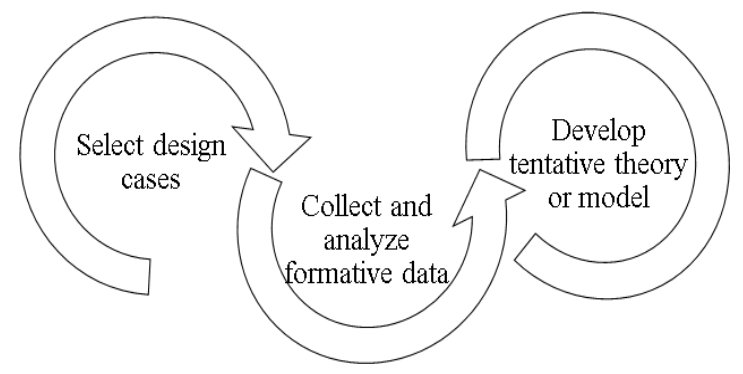

Figure 1. The steps of in vivo naturalist formative research.

\section{The Design Cases and Participants}

The researchers examined the processes of redesigning two courses (Human-Computer Interaction-HCI and Scientific Research Methods-SRM), which were already being taught face-to-face at the time, to be delivered through distance education by two design teams consisting of 13 graduate students who came together within the scope of a graduate course titled Distance Education Course Design. The design process lasted 11 weeks in total. To be closer to the research area, one of the researchers participated in the design process as a participant-observer. This researcher adopted the role of a participant and attended the SRM course design activities as a team member.

The demographic characteristics of the designers and information regarding their instructional design and DE course experience were obtained using a demographic data survey administered at the beginning of the design process. Table 1 presents these characteristics.

Table 1

Demographic Characteristics of the Designers and Information Regarding their DE Experiences

\begin{tabular}{|c|c|c|c|c|c|c|}
\hline $\begin{array}{l}\text { Course } \\
\text { Designed }\end{array}$ & Gender & Age & $\begin{array}{c}\text { Educational } \\
\text { Level }\end{array}$ & $\begin{array}{c}\text { Instructional } \\
\text { Design } \\
\text { Experience }\end{array}$ & $\begin{array}{c}\mathrm{DE} \\
\text { experience } \\
\text { as a } \\
\text { student }\end{array}$ & $\begin{array}{c}\mathrm{DE} \\
\text { experience } \\
\text { as a } \\
\text { designer }\end{array}$ \\
\hline SRM & Male & 33 & $\mathrm{PhD}$ & $\begin{array}{c}6 \text { years or } \\
\text { over }\end{array}$ & No & No \\
\hline SRM & Male & 24 & MSc & $3-5$ years & No & Yes \\
\hline SRM & Female & 25 & $\mathrm{PhD}$ & $0-2$ years & No & Yes \\
\hline SRM & Female & 26 & $\mathrm{PhD}$ & $0-2$ years & No & Yes \\
\hline SRM & Male & 26 & MSc & No & No & No \\
\hline SRM & Male & 28 & MSc & $3-5$ years & No & No \\
\hline $\mathrm{HCI}$ & Female & 25 & MSc & $3-5$ years & Yes & Yes \\
\hline $\mathrm{HCI}$ & Male & 27 & $\mathrm{PhD}$ & $\begin{array}{c}6 \text { years or } \\
\text { over }\end{array}$ & No & No \\
\hline
\end{tabular}




\begin{tabular}{lcccccc} 
HCI & Male & 25 & PhD & $3-5$ years & Yes & Yes \\
HCI & Female & 25 & BSc & 0-2 years & Yes & No \\
HCI & Female & 25 & PhD & 3-5 years & Yes & Yes \\
HCI & Male & 23 & MSc & 0-2 years & Yes & No \\
HCI & Female & 25 & MSc & 0-2 years & No & No \\
\hline
\end{tabular}

Among the participants aged between 23-33, seven (54\%) were male and six (46\%) were female. Six of the designers (46\%) were master's students, and six (46\%) were PhD students, while one designer (8\%) had an undergraduate degree, but was taking the course as a guest student. Five of the participants (38.5\%) had less than 2 years of instructional design experience, five (38.5\%) had $3-5$ years, and two (15\%) had 6 years or longer, while one (8\%) had no instructional design experience. Five of the designers (38.5\%) had experienced being a student in DE, and six (46\%) had participated in a DE course design process.

The SRM and HCI courses that were subject to the design cases were being taught by the same instructor without the support of assistants at the time. To obtain information from the instructor, the demographic data survey and his personal website were used. The instructor of the course was a 36-year-old male. The instructor, who had knowledge of advanced instructional design and development, participated in a DE process in the past due to organisational or individual reasons, and taught several courses through DE.

\section{Instruments}

The data-gathering tools used in the study were the logbooks that the designers kept during the design process, individual and focus group interviews, the demographic data survey, and personal Web pages prepared by the designers prior to the design process so that they could get the chance to know each other such as contact information, personal characteristics (likes, dislikes, interests, and so on), information and communication technology (ICT) knowledge and experience, and thoughts about team projects. The Web pages also contained a photograph of the designers.

\section{Data Collection}

The data for the study were gathered in interactive and non-interactive steps. The interactive datagathering involved directly interacting with the designers. These were the individual and the focus group interviews that were conducted with the designers in the design process. The non-interactive datagathering step did not involve directly interacting with the designers. These were the individual field notes kept as logbooks by the members of the design team, the web pages that they prepared in the first week of the course Distance Education Course Design to easily access information regarding each other, and thus get to know each other at the beginning of the design processes, and the demographic data survey prepared to gather data on the participants' demographic characteristics, and their experiences of instructional design and DE.

In the logbooks, the designers took notes regarding their feelings, thoughts, and field notes about the design process conducted for the DE course design and the project, team meeting records, and other data

related to other elements of design including the date and time of each entry. Semi-structured interviews were conducted with the designers at the end of the design process. The interview questions were mostly 
about their experiences in the design process, its positive and negative aspects, and how the designs could be improved. To ensure the internal validity of the interview form, expert opinion was used, and the interview form was finalised based on their feedback. The interviews were conducted in the designers' office when possible or online. The interviews were recorded using an audio recording device to make the data confirmable and ensure its integrity. Five of the participants did the interview in person, six participants did it as an online audio call, and two participants did it by e-mail. After the HCI and SRM course design projects were submitted, focus group interviews on the design experience and its positive and negative aspects were conducted with the two design teams separately.

\section{Data Analysis}

The study's approach was similar to Glaser and Strauss's (1967) grounded theory approach, which develops a theory or a model using induction on data that have been gathered and analysed systematically.

In grounded theory, the data are gathered based on cases, rather than variables. The concepts or constructs on which the theory or model is based are not determined at the beginning of the research process, but generated from data collected during the process (Corbin \& Strauss, 2015). Data gathering and data analysis are embedded in each other (Charmaz, 2014; Corbin \& Strauss, 2015). Data analysis begins as soon as the first data are gathered, and each analytical finding is used as input in the next datagathering process. This approach is usually used for design-based research employing the grounded theory approach. The aspect of this study that differs from design-based research studies is the cases and the data-gathering processes being conducted simultaneously, not successively. In the grounded theory approach and design-based research, the focus is on iterative processes, and the data from one case supports another case (Baş \& Akturan, 2008; Glaser \& Strauss, 1967; Wang \& Hannafin, 2005; Yıldırım \& H., 2008). To obtain richer data content, the cases were dealt with simultaneously, and the data were gathered simultaneously. To thoroughly examine the large amount of data obtained and bring different perspectives to the study, multiple researchers were included in the data analysis process. The interviews and the logbooks were analysed using content analysis. The individual interview data were used to support the rest of the data and confirm the design model.

The data were transferred to the electronic environment before moving on to the analysis. When the datagathering was completed, it yielded 181 single-spaced pages in 12 point Times New Roman font. The data were transferred to Nvivo 8.o software for analysis. The analysis process started with open coding. Two researchers worked together in the coding process with the intention of ensuring common understanding, and so completing coding process shorter and more efficient. The data were read line-by-line, the meanings of the statements were discussed, and the coding was done when there was $100 \%$ agreement to ensure its reliability. After a sufficient amount of codes were revealed, the researchers deduced categories by associating free codes. After this step, which is called axial coding, the coding process continued based on the categorical structure revealed. The coding process started with the logbooks. When deciding on the data source to continue the coding with, the number of codes revealed from this data cluster and the categorical or thematic variety of these codes were considered. Categorical saturation was achieved with 215 codes generated when the first five logbooks and the focus group interviews were analysed. A total of 258 codes were obtained by the coding process. The set of codes and categories obtained as a result of the 
coding process were reviewed, and finally, 13 categories were formed. These categories were first task, team dynamics, preliminary search for design, analysis, general framework of the course, software, limitations, privacy, integration, tests, problems, interface improvements, and support.

\section{Validity and Reliability}

The primary concern for a design theory or model is to what extent it is better than other methods at reaching the desired outcomes or preferable to them (Reigeluth \& Frick, 1999, p. 634). For design theories or models to be preferable in this way, they need to meet three criteria: effectiveness, efficiency, and appeal. Since this study is based on grounded theory, and iterative processes or comparative analysis approaches were not followed, these criteria were not met. In addition to preferability, Reigeluth and Frick (1999) proposed that methodological concerns should be dealt with in three groups: construct validity, suitable data-gathering and analysis (internal validity or accuracy), and generalizability to a theory or model.

Yin (1984) proposed three strategies to enhance construct validity: using different types of data sources, forming a data (evidence) chain, and receiving feedback from participants for the case report. To draw a comprehensive conclusion from the two design processes, data triangulation was ensured, and a variety of data-gathering techniques such as logbooks, and individual and focus group interviews were used. To form an evidence chain, the designers recorded every step they took in their logbooks. The design model proposed at the end of the research process was presented to the designers, and their feedback was obtained using model checking.

The researchers attempted to create an honest and open atmosphere for the data-gathering process so that the designers could share their ideas about the cases more freely. The interviews with the designers started with general questions about the process in a semi-structured format, and then went into specific issues depending on the participants' responses. Various measures were also taken to eliminate researcher assumptions, bias, and theoretical orientations in the study. For the coding to be done in an open-minded and objective way, and to restrain theoretical orientations, two researchers were included in the analysis process. To conceal the real identities of the designers during the data analysis, aliases were used.

Reigeluth and Frick (1999) identified contingency specification and replicating the study as ways to enhance the generalizability of the results. In this study, two design cases were examined simultaneously so that richer conclusions were drawn from these cases, and contingencies were specified from a broad perspective by comparing the results.

\section{Results}

Since there were many question marks in the designers' minds at the beginning of the design process, they had difficulty directing their work. In face-to-face and online communications, when asked what was expected of them, the designers stated that they were not able to form a common understanding in the initial weeks. 
Analysing the first task code showed that, at the beginning of the project, the teams had many questions in mind. Course syllabi and student outcomes from previous years and interviews with the instructor-in other words, the customer for the design-usefully addressed these uncertainties and determined a road map. In addition, forming a communication network and establishing sharing environments for the teams were among the prioritised tasks.

\section{Team Dynamics}

The first stage of the instructional design or development process comprised of forming the design teams. The sub-themes of teamwork, team interaction, project management and decision-making, task assignment, social relations and this category's 35 codes constituted the human dimension of the Webbased course design and development process.

Online course design is a complex process that requires knowledge of pedagogy and technical expertise, and it is unusual for the same person to have all these skills. For this reason, e-course design starts with assembling the design team. A design team consisting of individuals with different competencies in technical design and instructional design facilitates the design process in terms of time and effectiveness. However, depending on the size of the e-course task being prepared, the number of designers should be at an optimum level. The most important problems caused by too many designers are communication problems and problems in creation of a common workplace. Increasing the number of designers also causes difficulties for team management, decision-making processes, social relations, and work effectiveness.

The initial tasks of the designers included preparing the sharing environment. In this step, the designers performed the tasks of sharing personal contact information (phone, e-mail, website and social networking addresses), establishing virtual working spaces, and organising periodical face-to-face meetings. Among the team components, administrative mechanisms should be created. It was found that having a project manager was good for speeding up the teams' decision-making processes and ensuring coordination among the designers. In e-course projects that do not have a manager or a coordinator, the importance of sharing within the team increases. The significance of planning activities done in the process is huge. If all team members participate in planning the design and actively contribute to the decision-making process, the design process progresses more effectively. In addition, task overlaps are avoided when task assignments are done after planning. When the design systematically progressed and the decision mechanisms made task assignments clear to the team members though, the design goals were achieved more quickly and had better quality in design cases.

The teams shared mostly by e-mail and used virtual group spaces and file hosting sites to share large files. In the later stages of the project, the need for more specialised sharing emerged. Since sharing was more intense between members working on the same tasks, it was conducted by synchronous communication, rather than asynchronous communication. According to Power (2009), the culture of instructional design cannot be limited to only theoretical knowledge or design skills. For this reason, designers should have interpersonal communication and adaptation skills. The team component constitutes the human dimension of e-course design. The designers' familiarity with teamwork, their leadership characteristics, 
communication skills, value judgements, and sense of responsibility are important parameters for the harmony of the team.

\section{Preliminary Search for Design}

After the formation of the design teams in the e-course design, the second stage was doing research on course design. It was observed that this research mostly concerned how the course would be delivered on the Internet, not what the course would be like. This category contained 10 codes. Especially the designers at the beginner level gained experience regarding the e-course design and acquired new perspectives during this step. The designers tried to raise the teams' awareness by sharing their DE experiences. The designers accessed the syllabi of similar e-courses and examine samples of DE course transformation to give them ideas about web-based courses. Additionally, the resources in the literature were reviewed, and DE course design strategies and models were examined for use in the course design process. The most distinguishing characteristic of this stage was the effort of the design team to form a design path or plan in light of their experiences, the research they did, the interviews they conducted with the instructor and the course data they obtained from him.

\section{Analysis}

Following the research on how the course would be provided over the Internet, next came the analyses of the nature of the course. This category that included the analyses and conclusions in the process of course preparation contained 24 codes.

In the DE course design process, the design of the environment being based on these analyses was a good idea. The analyses affected a wide variety of design elements ranging from instructional activities to software and from student motivation to support services. Analyses were conducted in different contexts during the various steps of the course preparation process. However, this step focused on identifying the course elements, and analysing the residential course, the instructor, and the students.

The course analysis included course content, course syllabus, student products and prior course evaluations, if any. In addition, the existing components of the residential course that were already on the Internet were examined. The students who took the residential course and those who could potentially take the course were interviewed, and their expectations from the course were identified. The students who were taking the residential course during the design process were regularly interviewed to obtain their views and suggestions on planning the design and arranging the environment. The instructor was not only a data source for the designers, but also a fellow traveller in the journey of design. The designers designed the online courses in cooperation with the subject area expert, the instructor. The literature reports that the institutions that supported the cooperative efforts between the instructor and the instructional design team yielded positive results (Knowles \& Kalata, 2007). Therefore, the designers frequently emphasised the need to stay in touch with the instructor. The weekly meetings organised between the designers and the instructor of the course brought functionality to the design process. In the meetings, the designers both reviewed the tasks they had performed from a formative perspective with the instructor and planned the tasks to be performed next. Many details that could not be seen by the designers and new perspectives were revealed in these meetings. The courses had been well-documented 
and structured in terms of content and syllabi, and this was an advantage for the designers in the analysis step. The designers' familiarity with the course content was another positive characteristic.

\section{Pedagogical and Technical System Design}

This section consisted of four categories including general framework of the course, software, limitations and privacy, and a total of 132 codes. The design stage was the stage in which the designers shared roles, and carried out the instructional and technical design processes separately. The design team that dealt with the instructional design attempted to determine the general framework of the course by presenting the course pedagogy, activities, and assessment criteria. During this process, the instructional design team intensely interacted with the course instructor. The patterns revealed by analysing the course syllabi from previous years were found to be helpful for the design. First, the course pedagogy was decided for the preparation of the instructional plans. Then, how this pedagogy would be reflected in the system, in other words, which activities would be implemented, became the topic of discussion. The DE course activities corresponding to the traditional instructional strategies were designed, and it was found that the burden that doing so brought in terms of the time and effort for the instructor and the designers should be carefully considered.

Some course documents that the course instructor gave to the designers were asked to be kept confidential and used only for design purposes. The instructor also required that a legal contract regarding confidentiality should be created. Moreover, the designers were also asked not to upload the presentations included in the textbook $\mathrm{CD}$ to the $\mathrm{DE}$ environment due to copyright restrictions.

The assessment criteria were used to decide how the student performance would be evaluated. In addition to the classical assessment techniques such as homework and exams, alternative techniques that were unique to DE were observed to come up, such as log records and checklists showing progress in the system, to evaluate the students' interaction with the system. After issues such as student communication, individual and group activities, instructor guidance, the sequence of the course components, textbooks and resources, lesson breaks, attendance, and the schedule of the face-to-face and DE course sessions were clarified, the instructional design plans were finalised by preparing the instructions.

The question of how the pedagogical structures would be technically actualised in the system should be answered. The technical design team took the responsibility of setting up the technical infrastructure and software in accordance with the course plans that were prepared. However, not every intended pedagogical structure could be transferred to the DE system due to limited budget and software capabilities. Such cases revealed the need to make pedagogical adaptations in the instructional plans. Since the pedagogical and technical structures affect each other in DE course design, the instructional design and technical system design were conducted simultaneously.

\section{Integration}

The process of uploading the course contents and activities that were prepared to the DE environment was explained in the e-course production category and its 21 codes. The pedagogical and technical structures were actualised on the DE system in the integration stage. In other words, the e-course was produced by uploading the course contents to the DE environment. In both design cases, the course 
productions were conducted easily and quickly. The designers' familiarity with the software reduced the time for uploading the contents to the environment. It was also observed that the designers' software experiences came in handy in this process. With the DE course in place, the visual arrangements of the environments began.

The transfer of the course to the DE environment enabled the instructor to see the tasks conducted more holistically and provide more sound feedback. The completion of uploading speeded up the work of the designers. The designers were able to test the system and find problems. In addition, preparations for the usability tests began.

\section{Tests}

This category contained 4 codes. The designers moved on to the system evaluation stage after introducing the DE course. The formative evaluation conducted until this stage was replaced by product evaluation. Before moving on to the user tests, the course environments were subjected to the team test. All the course components were tested. Design-related and technical problems were eliminated, and the usability tests were prepared. Usability tests are used to detect problems in the user interface, to prevent interaction inefficiencies and to develop user-friendly designs. These tests also reduce orientation time and enhance effectiveness, efficiency, and user satisfaction (Norman \& Panizzi, 2006). In the usability tests, the users were assigned authentic tasks in the environment, and their interactions with the system were evaluated. The usability tests were administered to the students and the instructor, and their views on the environment were obtained after the test. Interface errors and interaction problems were revealed in this process, and data for a more user-friendly system were gathered. The designers found many errors that they were unable to foresee, and thus stated that these tests were very useful.

\section{Improvements}

This section's categories are problems, interface improvements, and support with 31 codes. In the improvements stage, the usability problems that emerged in the usability tests were eliminated, and visual improvements and arrangements were made to enhance interaction. One of the most important benefits of the usability tests was that it revealed where and when users needed support. The designers prepared user support training. The orientations to be given during the course were set up with the instructor. The designers prepared the system's user manual for the instructor. The version of the system in the test environment was added to the institution's system. At this point, founding a technological support unit was discussed, but it was decided that only the student assistants would deal with technical issues due to financial limitations.

\section{Discussion}

As the online learning technologies develop, students and educators use different tools, distribution systems, and instructional management systems (Alexander, 2006; Al-Senaidi, 2008; Grosseck, 2009). Although online course design includes many components and processes that also occur in traditional instructional design, it also requires approaches unique to the online environment. In spite of the general design principles that would guide the production of learning environments, how these principles should be concretised in the e-learning environment is a point to be considered (Herrington, Reeves, \& Oliver, 
2010). This study, based on authentic design cases, proposes a design model to guide instructors who want to put their courses on the Internet.

The model was developed with a grounded approach in light of the codes and categories revealed by the researchers to focus on the phenomenon more comprehensively and easily. The model consists of seven basic stages (rings) and a number of sub-stages in each stage (see Figure 2). In the stages, the starting steps are shown in grey colour. The design strategy that is dominant in the transitions between the stages is shown in the arcs around the top of the rings. Similarly, the type of evaluation that is dominant in the stages is specified in the arcs drawn in the bottom of the rings. The instructor has a key role and should be met with regularly for ideas and suggestions about the design process.

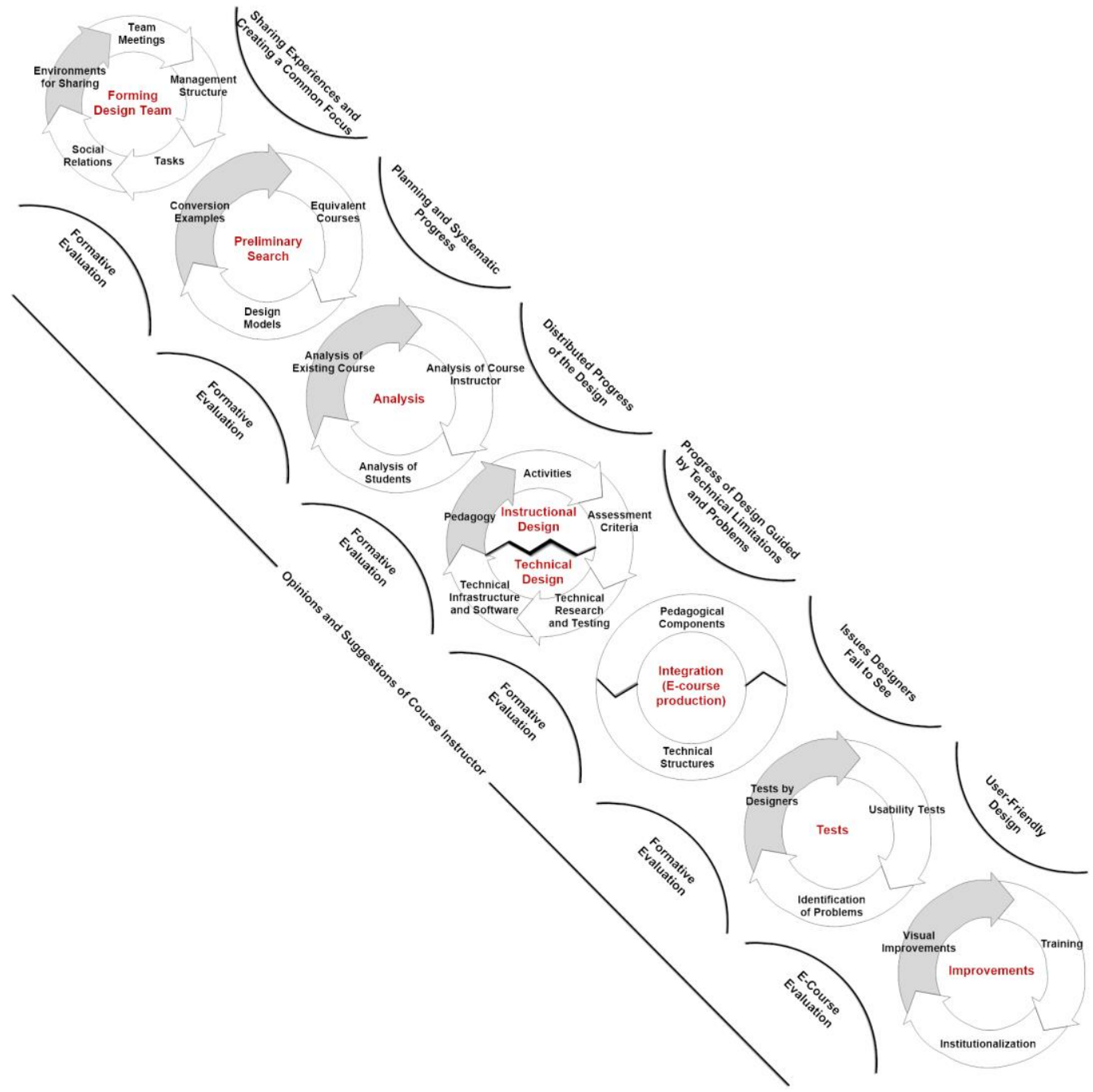

Figure 2. Experience-based e-course design model.

The flow of the experience-based e-course design model is presented in Figure 3. The black squares represent the main stages, and their location on the flow chart shows when they start. Straight lines indicate that the impact of respective design phase is strong in a temporal manner, while the dashed lines 
indicate that the effect is reduced. Evaluation is an important component of the entire process and affects all stages. Straight lines at the top indicate that the type of evaluation is formative, and dashed lines indicate that it is product-oriented.

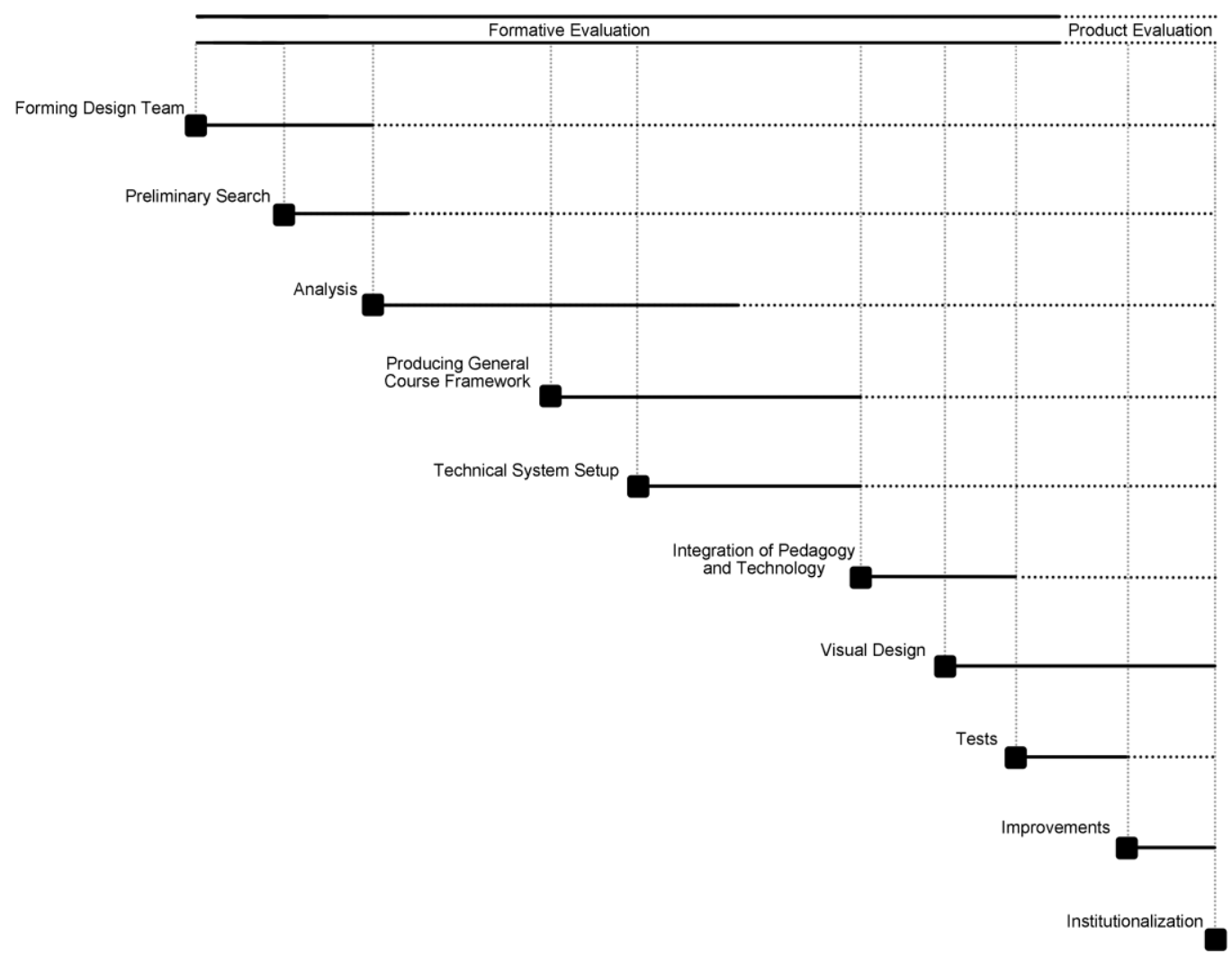

Figure 3. Process flow of experience-based e-course design model.

The experience-based e-course design model resembles some DE course design models or approaches in terms of the designer's collaboration with the instructor or subject matter expert (for instance Alvarez et al., 2005; Power, 2009). Although the model reminds the components of conventional instructional design, it includes many distinctive design phases such as forming a design team, carrying out a preliminary study, separating pedagogical and technical elements in the design phase and integrating them in the integration phase, and having formative evaluation processes nested in stages. The experience-based e-course design model provides a design route that can be followed step by step from beginning to end. In addition, the process flow model makes a unique contribution to the literature since it shows how the components of the model are located temporally.

The instructional design process in DE differs from classical instructional design. In classical instructional design, after the needs are identified, pedagogical strategies and tools (such as media) are selected for these needs, and the financial aspect of the task is not usually considered. However, in authentic course design, the situation is a little different, and the concepts of pedagogical structure, efficiency, and technological feasibility interfere with each other. 
DE requires specific software to implement pedagogical strategies, and there is a wide variety of it. Most software costs money. Software costs can be exorbitant, so educators and designers may turn towards suitable free tools. However, the selection of technological tools at a suitable price can affect the pedagogy of the course in various ways. The following quote from a designer's logbook is an example of this issue:

The Ivisit Presenter videoconference tool is a closed-system distance group interaction platform that enables the online sharing of screens, documents, applications, and live video calls with groups of 8 to 10 individuals for free. Although this tool cannot meet the needs of all 65 individuals in the SRM course, it could be used for our e-course if each group member makes a weekly presentation to smaller groups from the class.

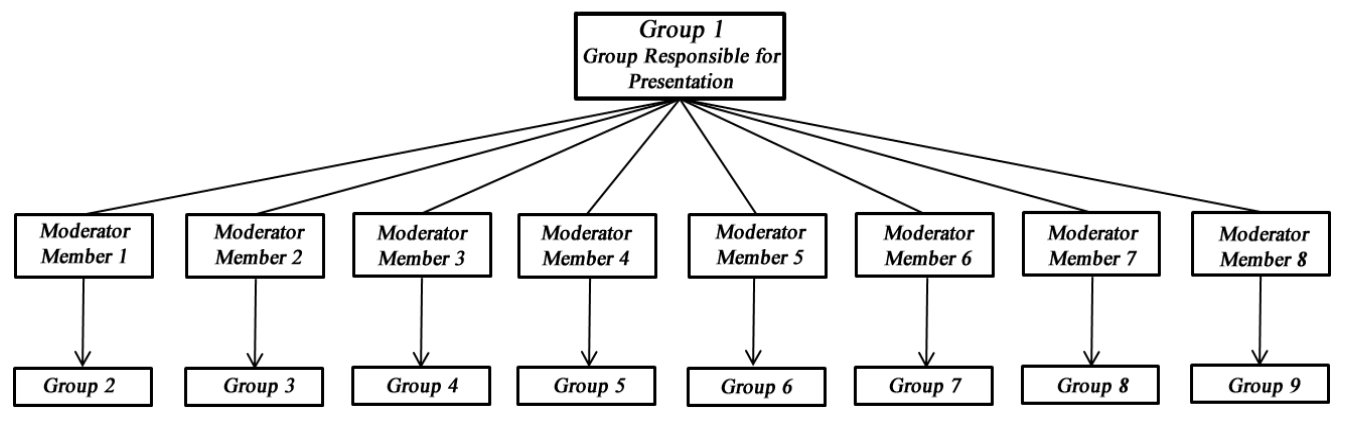

Figure 3. The model proposed by the SRM course designers for student presentations.

In this example, in order to benefit from this free tool with a low user capacity which was found while searching for software for presentations to the class, the designers proposed amendments to the pedagogical structures to the instructor, offering the idea of holding parallel presentation sessions with small groups rather than sessions with the entire class (see Figure 4). Many similar situations were experienced in the design cases. Some pedagogical elements that were not technically possible were either removed from the instructional plans, or various pedagogical adaptations were made to the available software tools. While the pedagogical choices were affected by the DE tools and the software, they were also affected by the results of the feasibility analysis. This brings to the fore DE's dilemma of technology according to pedagogy or pedagogy according to technology.

The pedagogical structures were not only affected by the software capabilities. Technical problems also emerged in the processes of setting up and integration of the software. Some of these problems and limitations caused changes in the design. Examples of these changes included students uploading their presentations as PDFs due to the language character problem that emerged in the file uploading process, and only the images of those who were presenting being on the screen because of the slowdown in the audio and video transmission speed due to large class size. Similar problems can emerge in delivering the course, and the e-learning process can be interrupted due to unexpected technical problems such as power outages, Internet unavailability, software failures, and user errors. For this reason, the plans made in the e-course process should be more detailed, systematic, and probabilistic than those in the 
instructional design of the residential course. The design should have the flexibility to deal with problems that emerge, and if necessary, the academic calendar should allot time for compensatory lessons.

DE course design is a multifaceted and complex process. No educator or designer can put all their knowledge and expertise in a course design and take on all the roles in the process. Thus, at any scale, elearning environment design requires teamwork. Although having individuals on the team with different abilities in instructional design and technical aspects is an advantage, the number of designers seems to be an important parameter. In design cases in this study, two separate design teams of six and seven individuals were assembled for the SRM and HCI courses, respectively. It was observed that team interaction became more important in the HCI course where the number of designers was slightly higher. The design team being crowded required the team to come to gather in the same physical environment, but at this stage, the online tools were found to be insufficient. This is because of the designers' need for intense interaction and cooperation at the beginning of the design process. This should be emphasised in DE course design.

One of the issues to be considered regarding the team components is the distribution of tasks and roles. There was a specific distribution of duties and roles after an overall framework was drawn up in the analysis stage. The designers designed the instructional and technical processes by forming two microteams within the team. Notably, the e-courses were being designed separately in terms of their instructional and technical aspects.

Another problem designers must cope with is the issue of submitting the e-courses on time. This pressure was felt throughout the design process, especially by the designers dealing with the technical aspects when the design was conducted separately. The micro-team doing the instructional design asked for the technical system's design to be completed to upload the course content to the DE environment before the usability tests. This increased the pressure on the technical designers who were dealing with the tasks of technical set-up and problems that emerged after the system tests.

Another issue that should be discussed is the variety and constant updating of the DE software tools. There are many software tools available that were developed by corporations and software development communities for DE. The software tools available on the market enable designers to design high-quality and effective courses quickly. However, there is no need to use these tools for every DE course. Furthermore, since it is relatively difficult to intervene in the software tools, the designers are limited by the software's capabilities, and this can cause some desired pedagogical characteristics not to be included in the design. In fact, whether to use available tools in software selection, or design a brand new system based on the needs is a tension that comes up in design cases. In current design cases, designers decided to use the available tools after considering the instructor's requests and time limitations. Another tension emerged at this stage. Which of the software tools on the market to select was an important problem. While the designers were trying to determine which features were needed, they also examined the features of the software tools available in the market. However, testing too many software tools can waste time and effort. This was due to inexperience with the software tools as well as not being able to decide on which one to choose. On the other hand, the tools and software used in DE are constantly developed, different products and versions are put on the market every day, and companies have different commercial policies depending on the conditions of the market. They even stop their service for some tools. DE courses are 
more sensitive to technology than residential courses. Thus DE courses need to be revised to keep up with developments in technology without relying on a tool for too long.

\section{Implications}

The flow of instructional design and development of Web-based courses is different from traditional instructional design. In traditional instructional design, the pedagogical strategies are identified based on needs, and the cost is for the most part not taken into consideration while choosing the appropriate technological tools. In Web-based courses, the issues of pedagogy, technology, and cost all affect each other. Moreover, the technical problems and setbacks that emerge during the set-up of the technological infrastructure unique to e-learning also affect pedagogical structures. For this reason, the pedagogical and technical designs should be conducted synchronously, and unlike traditional instructional design, the costs should be considered.

Constant communication should be established with the instructor, who is in the position of the subject area expert and the customer, and should give feedback regularly during the design process. Regular meetings with the instructor were quite beneficial in these designs, as the designers frequently emphasised.

Whether small-scale, such as a learning topic, or large-scale, such as an instructional curriculum, WBE preparation requires teamwork. The pedagogical and technical competencies of the team members are of significance, as well as their interpersonal skills and familiarity with teamwork. In addition, the number of the team members should be at an optimum level so as not to impair communication and collaboration between designers. This study demonstrated that a team of six or seven individuals were sufficient to redesign a residential course as DE in 11 weeks.

In parallel with developments in ICT, the software tools for DE are being developed continuously and are being diversified day by day. DE courses are more sensitive to technology than residential courses. Accordingly, the hardware infrastructure and software tools used in DE should be frequently reviewed, and the DE courses should be revised to keep up with developments in technology.

Although the Web has long been used as a tool for the dissemination of knowledge, how teaching on the Web should be designed and how the Web can be used as an effective instructional tool have not been fully understood (Suziki \& Tada, 2009; Tüzün, 2001). The present study has a significant potential for Web-based course design. The experience-based e-course design model can serve as a model for transforming residential courses into e-courses and provide open guidance to designers. The model can be used for future DE development either in a strict way or with some phases being skipped. However, there is a need for further research to test the validity and reliability of the model in different design cases. The effectiveness, efficiency, and appeal of the model should also be evaluated. It is not really possible for studies that develop and test design theories or models to be successful in one go. To achieve this goal, studies that test the model, in other words, iterative processes are needed. Formative research on course designs that adopted the model can contribute to revealing its strengths and weaknesses, present new ways to develop it, and make it even more preferable. 


\section{Conclusion}

Online learning has brought about distance and lifelong learning by using ICT, and has become the new paradigm of learning and teaching (Chen, 2007). Today, most academic institutions, particularly at higher education levels, have adopted the approach of teaching anytime anywhere, and transferred part or all of their traditional teaching to on-line environments. With the temporal and spatial flexibility of the Internet, institutions organise online courses and programs to meet student need not only during the semesters, but also during vacations and breaks. Thus, many instructors and instructional designers are asked to design online courses or transfer residential programs to DE. However, many instructors who face the task of online course design get stuck between technology and pedagogy (Herrington, Oliver, \& Herrington 2007). In the process of designing courses for the Web environment, educators and instructional designers have difficulty implementing pedagogical strategies in this environment, and this results in electronic content that is not blended with the appropriate pedagogy. This situation usually yields learning environments in which outdated pedagogies are merely repeated with technology added. This raises the questions of how pedagogic structures should be transferred to DE and how they can be adapted to DE.

The present study has a significant potential for Web-based course design. Based on the findings from the two authentic design cases, a design model consisting of seven basic stages including forming design team, preliminary search, analysis, instructional and technical design, integration, tests, and improvements was proposed to provide a route for both designers and educators. As such, whether aiming to convert the existing courses or to support in-class activities, it is considered that using an experiencebased model in designing Web-based courses will not only make the design process more efficient but also lead to a Web-based course of higher quality.

The participants in the study were designers with varying levels of experience with instructional design and DE course development, and the DE course design efforts were limited to 11 weeks. Since the sample design cases were simultaneous, the researcher participated in only one of the design teams. These limitations should be considered in the evaluation of the findings.

\section{Acknowledgments}

Authors would like to thank Dr. Charles M. Reigeluth and Dr. Michael H. Molenda for guiding the initial efforts of this work in early 2000's.

\section{References}

Al-Senaidi, S. (2008). Integrating Web 2.0 in technology based learning environment. In C. J. Bonk, M. M. Lee, \& T. Reynolds (Eds.), Proceedings of world conference on e-learning in corporate, government, healthcare, and higher education 2008 (pp. 541-545). Retrieved from http://www.editlib.org/p/29657

Alexander, B. (2006). Web 2.0: A new wave of innovation for teaching and learning? Educause Review, $41(2), 33-34$. 
Alvarez, D. M., Blair, K., Monske, E., \& Wolf, A. (2005). Team models in online course development: A unit-specific approach. Journal of Educational Technology \& Society, 8(3), 176-186.

Balcı, B. (2010). E-öğrenme programı tasarım süreçleri. In G. Telli-Yamamoto, U. Demiray, \& M. Kesim (Eds.), Türkiye'de e-öğrenme: Gelişmeler ve uygulamalar (Vol. 1, pp. 83-110). Ankara: Cem Web Ofset.

Baş, T., \& Akturan, U. (2008). Nitel araşttrma yöntemleri NVivo 7.o ile nitel veri analizi. Ankara: Seçkin Yayıncillk.

Burke, L. A. (2005). Transitioning to online course offerings: Tactical and strategic considerations. Journal of Interactive Online Learning, 4(2), 94-107.

Charmaz, K. (2014). Constructing grounded theory (2nd ed.). Thousand Oaks, CF: Sage.

Chen, S. J. (2007). Instructional design strategies for intensive online courses: An objectivistconstructivist blended approach. Journal of Interactive Online Learning, 6(1), 72-86.

Corbin, J., \& Strauss, A. (2015). Basics of qualitative research: Techniques and procedures for developing grounded theory (4th ed.). Thousand Oaks, CA: Sage.

Duchastel, P. (1996). A Web-based model for university instruction. Journal of Educational Technology Systems, 25(3), 221-228.

Gazioğlu, S. (2013). Online course design: A statistics course example. Teaching Statistics, 35(2), 98-102. doi: 10.1111/j.1467-9639.2012.00523.x

Glaser, B., \& Strauss, A. L. (1967). Discovery of grounded theory: Strategies for qualitative research. Chicago, IL: Aldine.

Grosseck, G. (2009). To use or not to use web 2.0 in higher education? Procedia - Social and Behavioral Sciences, 1(1), 478-482. doi: 10.1016/j.sbspro.2009.01.087

Herrington, J., Oliver, R., \& Herrington, A. (2007). Authentic learning on the web: Guidelines for course design. In B. Khan (Ed.), Flexible learning in an information society. Hershey, PA: Information Science.

Herrington, J., Reeves, T. C., \& Oliver, R. (2010). A guide to authentic e-learning. London, UK: Routledge.

Knowles, E., \& Kalata, K. (2007). A model for enhancing online course development. Innovate: Journal of Online Education, 4(2). Retrieved from: www.editlib.org/d/104333

Kokić, I. B., Nevin, A., \& Malian, I. (2013). Collaborative online course development: Facilitation of multidimensional teaching and learning. Croatian Journal of Education, 15(2), 491-519. 
Koontz, F. R., Li, H., \& Compora, D. P. (2006). Designing effective online instruction: A handbook for Web-based courses. Lanham, MD: Rowman \& Littlefield Education.

Lightfoot, J. M. (2000). Designing and implementing a "full-service" ClassPage on the Internet. Journal of Educational Multimedia and Hypermedia, 9(1), 19-33.

Neuhauser, C. (2004). A maturity model: Does it provide a path for online course design? The Journal of Interactive Online Learning, 3(1), 1-17.

Norman, K. L., \& Panizzi, E. (2006). Levels of automation and user participation in usability testing. Interacting with Computers, 18(2), 246-264.

Power, M. (2009). A designer's log: Case studies in instructional design. Athabasca, AB: Athabasca University Press.

Reeves, T., \& Reeves, P. (1997). Effective dimensions of interactive learning on the World Wide Web. In B. Khan (Ed.), Web based instruction (pp. 59-66). Englewood Cliffs, NJ: Educational Technology.

Reigeluth, C. M. (1999). What is instructional-design theory and how is it changing? In C. M. Reigeluth (Ed.), Instructional design theories and models (Vol. 2, pp. 5-28). Mahwah, NJ: LawrenceErlbaum.

Reigeluth, C. M., \& Frick, T. W. (1999). Formative research: A methodology for creating and improving design theories. In C. M. Reigeluth (Ed.), Instructional design theories and models (Vol. 2, pp. 633-652). Mahwah, NJ: Lawrence-Erlbaum.

Ritchie, D. C., \& Hoffman, B. (1997). Incorporating instructional design principles with the World Wide Web. In B. H. Khan (Ed.), Web-based instruction (pp. 135-138). Englewood Cliffs, NJ: Educational Technology.

Snyder, M. M. (2009). Instructional-design theory to guide the creation of online learning communities for adults. TechTrends, 53(1), 45-57.

Suziki, K., \& Tada, N. (2009). A layers-of-quality model in online course design: The five-e model. International Journal for Educational Media and Technology, 3(1), 92-103.

Swan, K., Day, S. L., Bogle, L. R., \& Matthews, D. B. (2014). A collaborative, design-based approach to improving an online program. The Internet and Higher Education, 21, 74-81. doi: 10.1016/j.iheduc.2013.10.006

Tüzün, H. (2001). Guidelines for converting existing courses into Web-based format. In Annual proceedings of selected research and development [and] practice papers presented at the 24th national convention of the Association for Educational Communications and Technology (pp. 360-370). Retrieved from http://eric.ed.gov/?id=ED470167 . 
Wang, F., \& Hannafin, M. (2005). Design-based research and technology-enhanced learning environments. Educational Technology Research and Development, 53(4), 5-23. doi: 10.1007/BFo2504682

Yıldırım, A., \& Şimşek, H. (2008). Sosyal bilimlerde nitel araştırma yöntemleri. Ankara, Turkey: Seçkin Yayıncilık.

Yin, R. K. (1984). Case study research design and methods. Beverly Hills, CA: Sage.

Zhou, C., \& Zhou, F. (2009). Website design for long-distance teaching based on SE-ID model. In 2009 ISECS International Colloquium on Computing, Communication, Control, and Management (Vol. 1, pp. 245-248). Sanya, China: IEEE. doi: 10.1109/CCCM.2009.5270458

\section{Appendix}

\section{Interview Questions}

1. Can you give an overall description of the design process? What did you experience?
a. What worked?
b. What did not work?

2. What went right during the design process?

3. What went wrong during the design process?

4. What kind of a design model did you follow for this project?

5. What benefits did you get from the interviews with the course instructor?

6. How did team interaction and intra-team communication go during the design process?

7. Can you describe the intra-team task-sharing and team solidarity?

8. What tests did you carry out before the e-course design product was presented to the students (the end users)?

9. Did you think of revising your design after these tests? Can you give a brief description of any such revisions?

10. What changes would you make in your design if you were to perform the same design process again? 
Guidelines for Transferring Residential Courses into Web Tüzün and Çınar

Athabasca

University

(c) 